\title{
The Liquid Sensor Using Thin Film Bulk Acoustic Resonator with C-Axis Tilted AlN Films
}

\author{
Ying-Chung Chen, ${ }^{1}$ Wei-Tsai Chang, ${ }^{1}$ Kuo-Sheng Kao, ${ }^{2}$ \\ Chun-Hung Yang, ${ }^{1}$ and Chien-Chuan Cheng ${ }^{3}$ \\ ${ }^{1}$ Department of Electrical Engineering, National Sun Yat-Sen University, No. 70, Lienhai Road, Kaohsiung 80424, Taiwan \\ ${ }^{2}$ Department of Computer and Communication, Shu-Te University, No. 59, Hengshan Road, Yanchao District, \\ Kaohsiung 82445, Taiwan \\ ${ }^{3}$ Department of Electronic Engineering, De Lin Institute of Technology, No. 1, Ln. 380, Qingyun Road, Tucheng District, \\ New Taipei 23654, Taiwan
}

Correspondence should be addressed to Chien-Chuan Cheng; chengccc@dlit.edu.tw

Received 15 September 2013; Accepted 1 October 2013

Academic Editor: Liang-Wen Ji

Copyright (C) 2013 Ying-Chung Chen et al. This is an open access article distributed under the Creative Commons Attribution License, which permits unrestricted use, distribution, and reproduction in any medium, provided the original work is properly cited.

Dual-mode thin film bulk acoustic resonator (TFBAR) devices are fabricated with c-axis tilted AlN films. To fabricate dual-mode TFBAR devices, the off-axis RF magnetron sputtering method for the growth of tilted piezoelectric AlN thin films is adopted. In this report, the AlN thin films are deposited with tilting angles of $15^{\circ}$ and $23^{\circ}$. The frequency response of the TFBAR device with $23^{\circ}$ tilted AlN thin film is measured to reveal its ability to provide dual-mode resonance. The sensitivities of the longitudinal and shear modes to mass loading are calculated to be $2295 \mathrm{~Hz} \mathrm{~cm}^{2} / \mathrm{ng}$ and $1363 \mathrm{~Hz} \mathrm{~cm}^{2} /$ ng with the mechanical quality factors of 480 and 287 , respectively. The sensitivities of the longitudinal and shear modes are calculated to be 0 and $15 \mathrm{~Hz} \mathrm{~cm}^{2} / \mu \mathrm{g}$ for liquid loading.

\section{Introduction}

Surface and bulk acoustic resonator devices are attracting increasing attention owning to their use in various novel sensors, including UV sensors, mass sensors, biosensors, and others [1-3]. Surface acoustic resonators have been developed and examined for potential sensor applications because they are cheap and small. However, surface acoustic resonators suffer from high insertion loss and poor power handling. Therefore, thin film bulk acoustic resonator (TFBAR) devices have been studied globally; they have a low insertion loss, a high power handling capability, small size, and high sensitivity [4-6].

Lakin classified FBAR devices into three types, which were via-isolated resonators, air gap-isolated resonators, and solidly mounted resonators [7]. The general purpose of these structures is to form a free or clamped interface beneath the resonance zone. This work develops a dual-mode TFBAR device based on an adapted via-isolated resonator with piezoelectric thin film whose c-axis is tilted. The back-etched cavity is used as the sensing area.
Despite the use of various piezoelectric films in TFBAR devices, including PZT, $\mathrm{ZnO}$, and AlN thin films [8-12], most of the many studies of piezoelectric thin films have focused on PZT piezoelectric materials. However, the use of PZT is limited for environmental reasons $[13,14]$. Hence, $\mathrm{ZnO}$ and AlN thin films have become the most promising materials for piezoelectric applications. This study concerns piezoelectric thin films of AlN, whose high quality factor makes them useful for elucidating the sensing properties of TFBAR for liquids.

TFBAR has two major resonance modes longitudinal and shear. The longitudinal mode is typically used when TFBAR is utilized as a communication device at high operating frequencies. For biosensor applications, the shear mode TFBAR is preferred [15]. Three approaches have been proposed to deposit tilted textured piezoelectric thin films. The first is sputtering with the changing of the configuration of the substrate. The second uses an additional blind between the target and the substrate in the sputtering system. The third involves the application of an additional electric field 


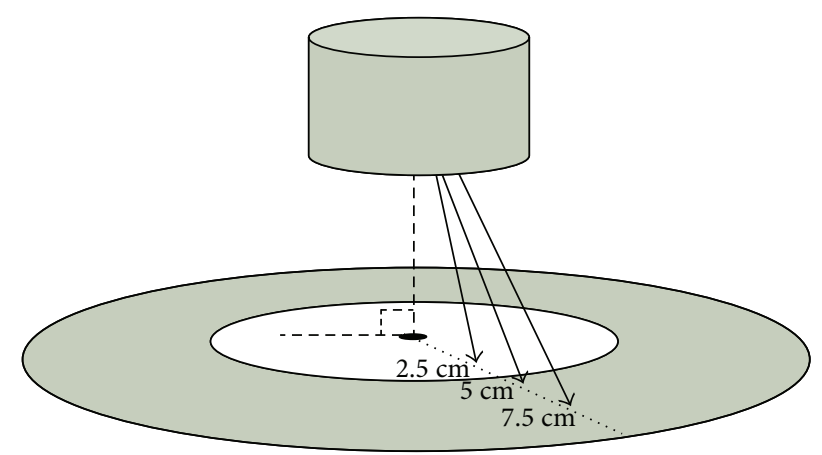

FIGURE 1: Schematic configuration of the off-axis deposition method.

TABle 1: Deposition parameters of Ti and Pt thin films.

\begin{tabular}{lcc}
\hline Target & $\mathrm{Ti}(99.995 \%)$ & $\mathrm{Pt}(99.995 \%)$ \\
\hline Substrate-to-target distance $(\mathrm{mm})$ & 50 & 50 \\
Base pressure (Torr) & $1 \times 10^{-6}$ & $1 \times 10^{-6}$ \\
Substrate temperature $\left({ }^{\circ} \mathrm{C}\right)$ & R.T. & R.T. \\
RF power $(\mathrm{W})$ & 75 & 175 \\
Sputtering pressure (mTorr) & 3 & 1 \\
Ar $(\mathrm{sccm})$ & 10 & 10 \\
\hline
\end{tabular}

during sputtering deposition [16-19]. However, the longitudinal mode is greatly damped in these methods. This study examines the c-axis-tilted AlN layer using the off-axis method with controlled sputtering pressure. Favorable dualmode frequency responses were obtained. Many scholars have studied liquid and biosensor applications, focusing on shear-mode resonators [20-24]. In this study, a multifunction TFBAR is simply fabricated for the use in mass and liquid sensors; these dual-mode TFBAR provide quantitative results, good sensitivity and a high quality factor.

\section{Experimental Method}

Since the performance of TFBAR depends on the storage of acoustic energy in the resonance zone, this area must be acoustically isolated. A via-isolated resonator is used in this study. The wet etching of (100) oriented silicon wafers is used forming a back-side cavity. Low-stress silicon nitride was deposited by low-pressure chemical vapor deposition (LPCVD) as the etching mask for the integrated FBAR device. After the substrates were cleaned using a normal process, the bottom electrodes, which comprised of platinum $(\mathrm{Pt})$ with an adhesive layer of titanium (Ti), were deposited by dualgun DC sputtering. AlN film has been found to be able to be deposited on a Pt layer [25]. Table 1 provides in detail the sputtering conditions for the preparation of $\mathrm{Ti}$ and $\mathrm{Pt}$ thin films.

Reactive radio-frequency $(\mathrm{RF})$ magnetron sputtering was utilized to deposit c-axis-tilted AlN piezoelectric thin films. The sputtering system was evacuated to a base pressure of $5 \times 10^{-7}$ Torr using a diffusion pump. The AlN piezoelectric thin films were deposited using the suggested off-axis method
TABLE 2: Deposition parameters of AlN thin films.

\begin{tabular}{lc}
\hline Target & $\mathrm{Al}(99.995 \%)$ \\
\hline Substrate-to-target distance $(\mathrm{mm})$ & 50 \\
Base pressure (Torr) & $5 \times 10^{-7}$ \\
Substrate temperature $\left({ }^{\circ} \mathrm{C}\right)$ & 300 \\
RF power $(\mathrm{W})$ & 250 \\
Sputtering pressure (mTorr) & 5,15 \\
$\mathrm{~N}_{2} / \mathrm{N}_{2}+\mathrm{Ar}$ & $46 \%$ \\
\hline
\end{tabular}

with a heated substrate [11]. Table 2 provides in detail the sputtering conditions for the preparation of piezoelectric AlN thin films with a tilted c-axis. Figure 1 also presents the off-axis deposition method adopted herein. Following the AlN thin films deposition, another $\mathrm{Pt} / \mathrm{Ti}$ layer was deposited on the designated area as the top electrode. After the sandwich structure had been formed, the cavity of TFBAR was formed by anisotropic wet etching using $30 \mathrm{wt} \% \mathrm{KOH}$ solution to provide high surface smoothness and a high degree of anisotropy [26], which was critical to the formation of a hopper cavity with a smooth bottom for holding liquid analytes. Figure 2 presents in detail the process by which the dual-mode TFBAR device was fabricated.

The preferred orientation and crystal properties of the AlN film were determined by X-ray diffraction (XRD) using a SHIMADZU XRD-6000 with $\mathrm{CuK} \alpha$ radiation. The cross sectional images of the AlN films were obtained by scanning electron microscopy (SEM) (Philips XL40 FESEM). The HP8720 network analyzer and CASCADE probe station (RHM-06/V + GSG 150) were used to measure the frequency responses of dual-mode TFBAR devices. The performance of the TFBAR devices in liquid sensing was performed using an automatic titrator (877 Titrino Plus).

\section{Results and Discussion}

3.1. Structural and Morphological Properties of Dual-Mode AlN Thin Films. The ideal physical properties of piezoelectric films for TFBAR applications are being a strongly orientated $\mathrm{c}$-axis and having a uniform surface morphology. The deposition parameters were varied herein to optimize the dualmode piezoelectric characteristics of RF-sputtered AlN thin films. In this investigation, off-axis distance and sputtering pressure were varied to determine the optimal growth parameters of the tilted piezoelectric thin film. In the first stage, the off-axis distances were controlled. Since particles with low kinetic energy reached the substrate, the competitive growth of inclined sputtering particles flux revealed the distinctive mechanism of crystal formation $[27,28]$. The kinetic energy of the particles was also affected by the mean free path of the particles, which was determined by the atmospheric pressure. Therefore, the sputtering pressure was set to $5 \mathrm{mTorr}$ and $15 \mathrm{mTorr}$ at $300^{\circ} \mathrm{C}$ to study its effect on the crystalline growth of AlN thin films. Heating improves the piezoelectric properties of AlN thin films.

As presented in Figure 3, excellent (002) orientated crystals can be obtained in samples at 15 mTorr with off-axis 


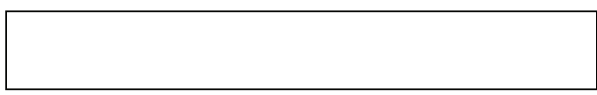

(a) Substrate cleaned by RCA process

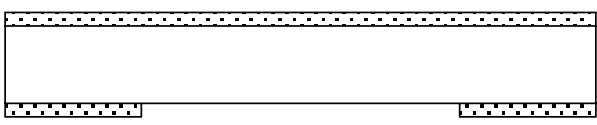

(c) $\mathrm{SI}_{3} \mathrm{~N}_{4}$ etched by RIE

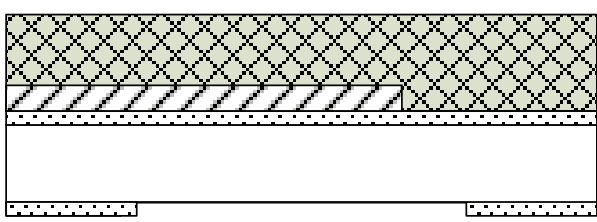

(e) AIN deposited by RF sputter
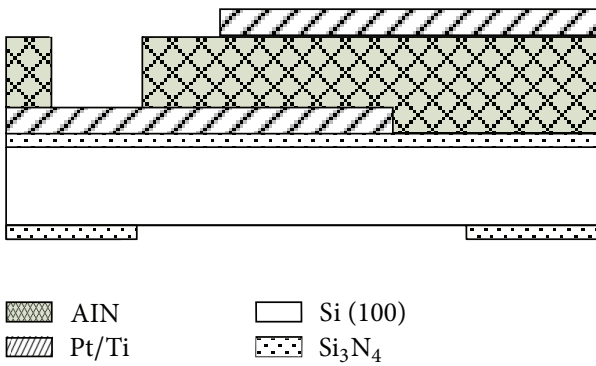

(g) Top electrode deposited by DC sputter

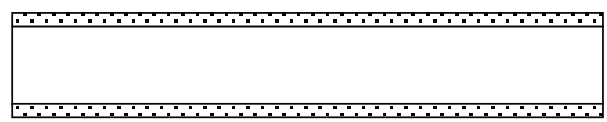

(b) $\mathrm{SI}_{3} \mathrm{~N}_{4}$ deposited by LPCVD

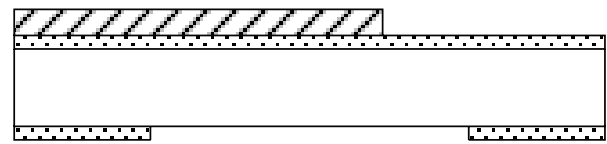

(d) Bottom electrode deposited by DC sputter

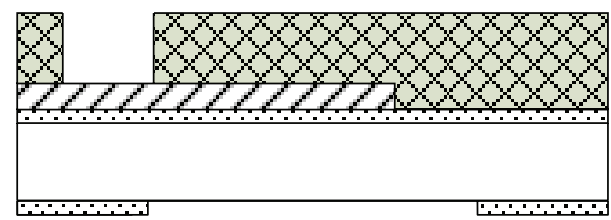

(f) AIN etched
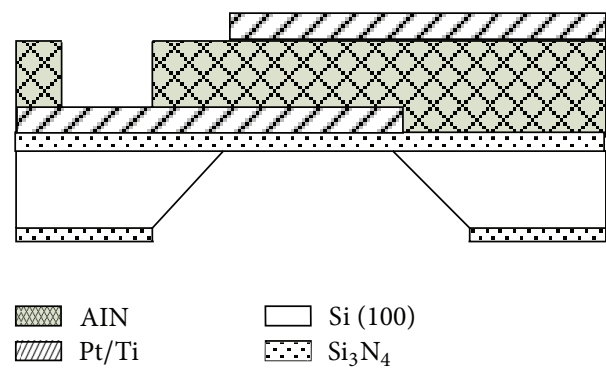

(h) Si etched by $\mathrm{KOH}$

FIgURE 2: The fabrication processes for the dual-mode TFBAR devices.

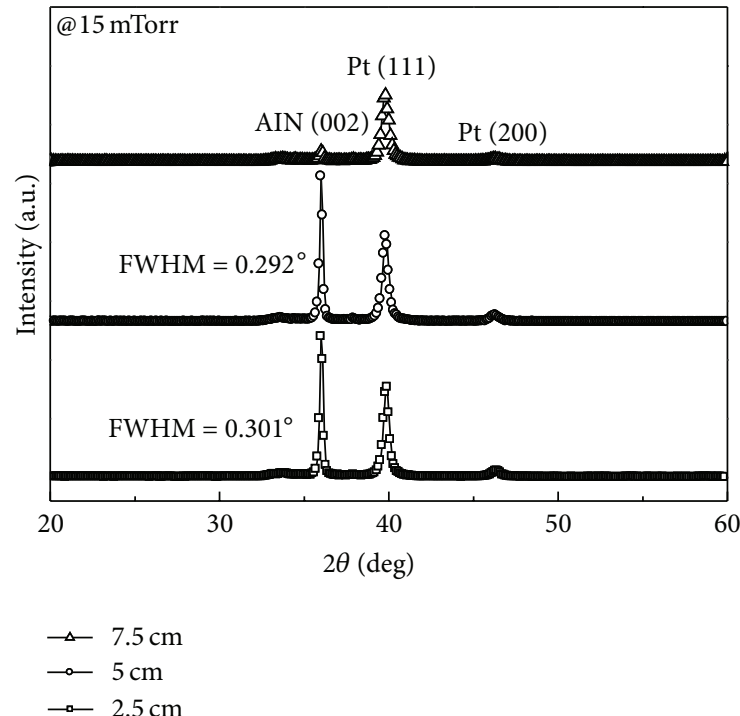

Figure 3: The $\theta-2 \theta$ X-ray scans of the AlN thin films deposited with various off-axis distances.

distances of $25 \mathrm{~mm}$ and $50 \mathrm{~mm}$. However, the experimental results reveal that only the sample with an off-axis distance of $50 \mathrm{~mm}$ had the c-axis-tilted structure, as shown in Figure 4. The sample with an off-axis distance of $50 \mathrm{~mm}$ and a larger caxis-tilted angle exhibited shear mode resonance. The kinetic energy of the particles was related to the sputtering pressure. To study the phenomenon of competitive growth of AlN thin films, two sputtering pressures of $5 \mathrm{mTorr}$ and 15 mTorr were used. The XRD patterns in Figure 5 reveal that AlN thin films that were deposited at 5 mTorr yielded a sharp (002) peak with a small full width at half maximum (FWHM). Additionally, as reveled by the cross sectional images in Figure 6, the sample with an off-axis distance of $50 \mathrm{~mm}$ under a sputtering pressure of $5 \mathrm{mTorr}$ exhibited enhanced competitive growth and had a larger c-axis-tilted angle of $23^{\circ}$.

To elucidate the relationship between the angle of tilt of the c-axis angle and the dual-mode resonance frequency responses $\left(f_{L}\right.$ and $\left.f_{S}\right)$ of TFBAR, two TFBAR devices were fabricated with the AlN c-axis tilted at $15^{\circ}$ and $23^{\circ}$. Figure 7 plots the frequency responses of two TFBAR devices. The TFBAR with the $15^{\circ}$-tilted AlN layer exhibited only a single resonant mode. The TFBAR device with the $23^{\circ}$-tilted AlN layer exhibited shear and longitudinal resonant modes at $1.17 \mathrm{GHz}$ and $2.07 \mathrm{GHz}$, respectively. These results reveal that not only a tilted piezoelectric layer but also a sufficiently tilted layer in the TFBAR devices can be excited to generate shear mode resonance. Therefore, an off-axis distance of $50 \mathrm{~mm}$ and a sputtering pressure of 5 mTorr are required to produce a highly textured and sufficiently tilted AlN piezoelectric layer for dual-mode TFBAR [29].

3.2. Sensitivity of Dual-Mode TFBAR for Mass Loading. Because titanium (Ti) has an inherently low density, it is 


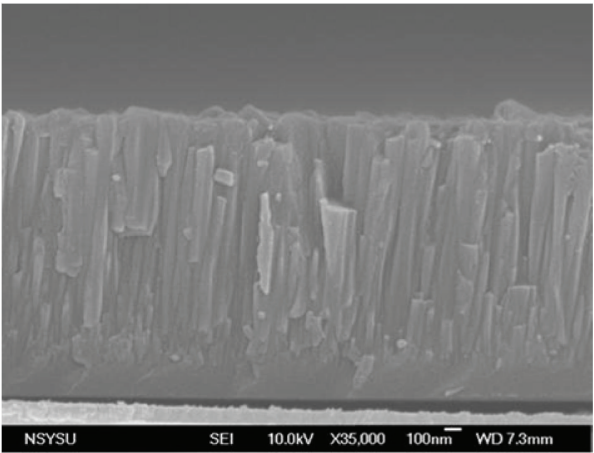

(a)

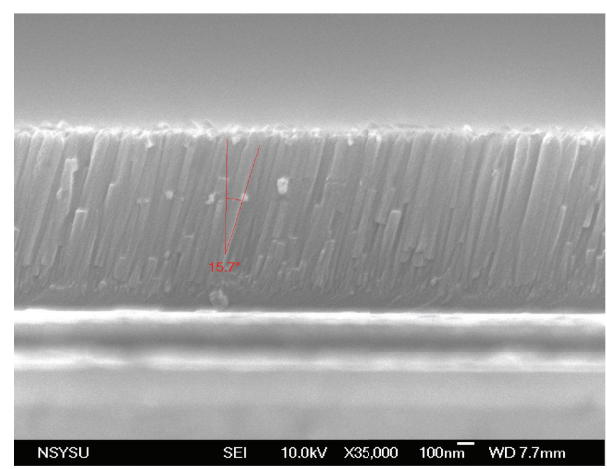

(b)

FIGURE 4: The cross sectional SEM images of AlN thin films deposited at 15 mTorr with off-axis distances of (a) 25 and (b) $50 \mathrm{~mm}$ from the center of substrate holder.

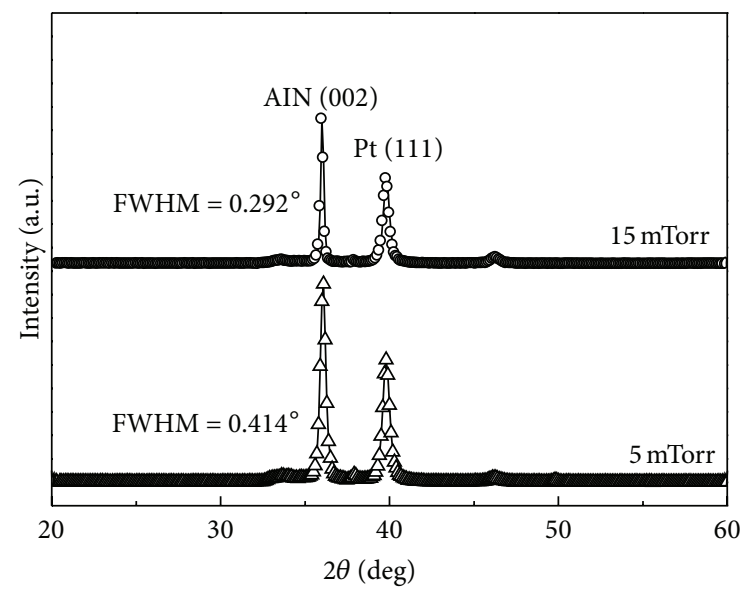

FIgUre 5: The $\theta-2 \theta$ X-ray scans of the AlN thin films deposited at $5 \mathrm{mTorr}$ and $15 \mathrm{mTorr}$ with off-axis distance of $50 \mathrm{~mm}$.

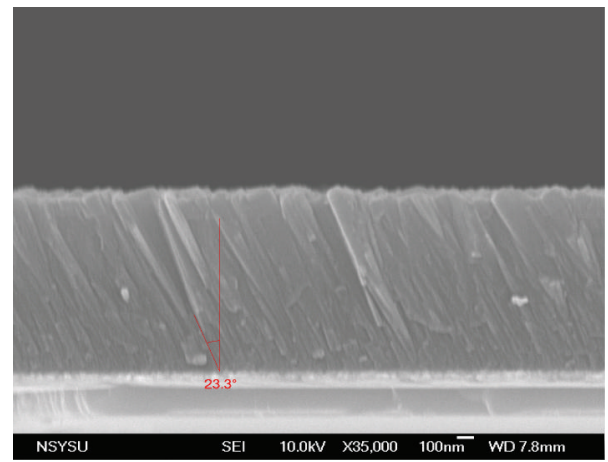

FIgURE 6: The cross sectional SEM images of AlN thin films deposited at $5 \mathrm{mTorr}$ with an off-axis distance of $50 \mathrm{~mm}$.

suitable for analyzing the sensitivity of TFBAR to a tiny mass. A Ti thin film was utilized herein as the mass loading material that adhered to the resonant zone that was exposed on the back cavity of the TFBAR device. Figure 8 displays a deposition rate of $0.46 \mathrm{~nm} / \mathrm{s}$ for sputtering the Ti mass loading. The thicknesses of the Ti layers were confirmed using the FESEM cross sectional images. Figures 9(a) and 9(b) plot the frequency responses of the longitudinal resonant mode $\left(f_{L}\right)$ and shear resonant mode $\left(f_{S}\right)$ of the dualmode TFBAR device with and without $\mathrm{Ti}$ mass loading, respectively. The variation of the central frequency under the Ti mass loading as the thickness of the mass increased to $4.6 \mathrm{~nm}$ was significant. In this study, the sensitivity of each mode of the TFBAR device to mass loading was estimated using the Sauerbrey equation [30],

$$
S_{m}=\lim _{\delta m \rightarrow 0}\left(\frac{\delta f}{f}\right)\left(\frac{1}{\delta m}\right) .
$$

The sensitivity of the longitudinal mode, calculated from (1), was $2295 \mathrm{~Hz} \mathrm{~cm}^{2} / \mathrm{ng}$, as presented in Figure 10(a). The calculated sensitivity of the shear mode was $1363 \mathrm{~Hz} \mathrm{~cm}^{2} / \mathrm{ng}$, as shown in Figure 10(b). These results reveal that the $S_{m}$ of the longitudinal mode was 1.7 times that of the shear mode. Clearly, the longitudinal mode of the dual-mode TFBAR device is preferable for mass sensing applications.

3.3. Sensitivity of Dual-Mode TFBAR in Liquid Environments. A gold ( $\mathrm{Au}$ ) layer was initially deposited onto the sensing area of TFBAR as the binding layer for the use in biochemical sensor. To improve the adhesion between the Au layer and the $\mathrm{Si}_{3} \mathrm{~N}_{4}$ layer, a chromium (Cr) layer was deposited by DC sputtering before the Au layer was deposited by the same method. Additionally, the surface of the Au layer was treated with oxygen plasma to enhance the hydrophilic properties of the Au layer and thereby promote migration of the liquid drop.

Since the frequency drift was caused by the extra $\mathrm{Au} / \mathrm{Cr}$ layer, as shown in Figure 11, the TFBAR device had to be calibrated before the follow-up test. Figures 12(a) and 12(b) plot the frequency responses of the dual-mode TFBAR device in a liquid environment (DI water). The longitudinal resonant mode $\left(f_{L}\right)$ almost disappeared as the liquid was dropped into the cavity of the device, whereas the shear resonant mode $\left(f_{S}\right)$ remained.

Since longitudinal resonance vanished in a liquid environment, the longitudinal frequency drift could not be used 


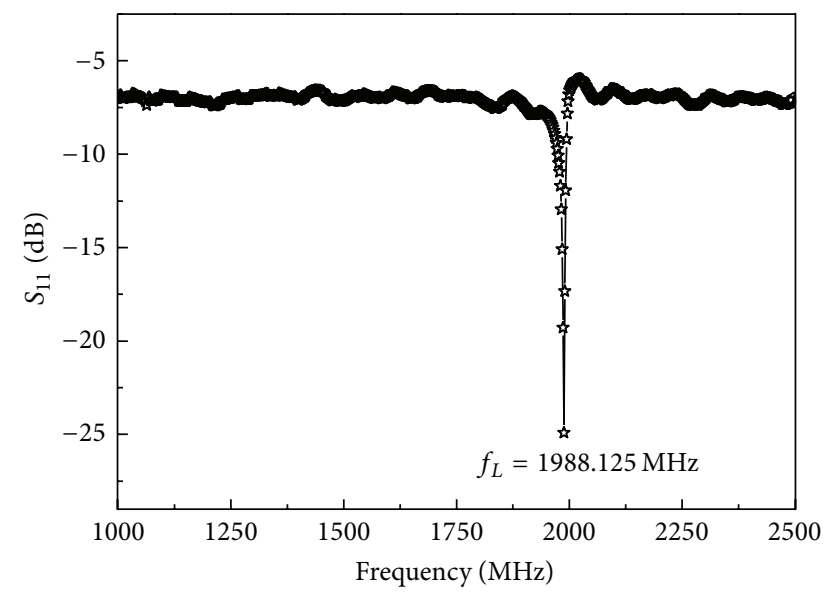

(a)

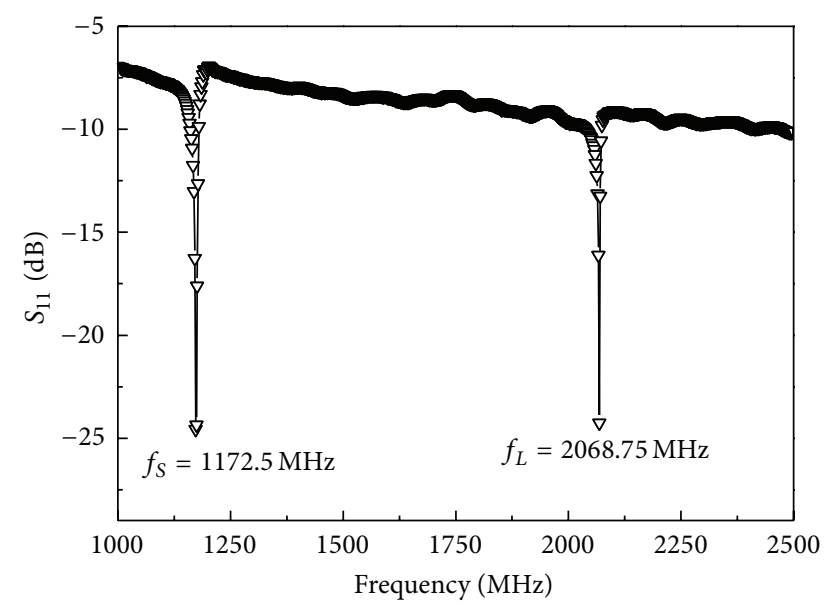

(b)

FIGURE 7: Frequency responses of TFBAR devices with (a) $15^{\circ}$-tilted and (b) $23^{\circ}$-tilted AlN layers.

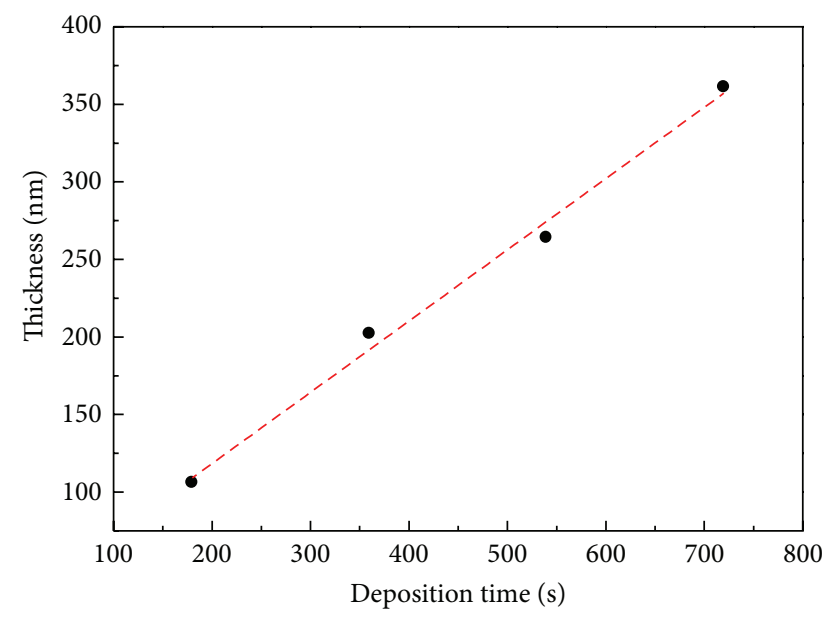

- Experiment

- - - Linear fit of experiment

FIgURE 8: The deposition rate of Ti layer as mass loading.

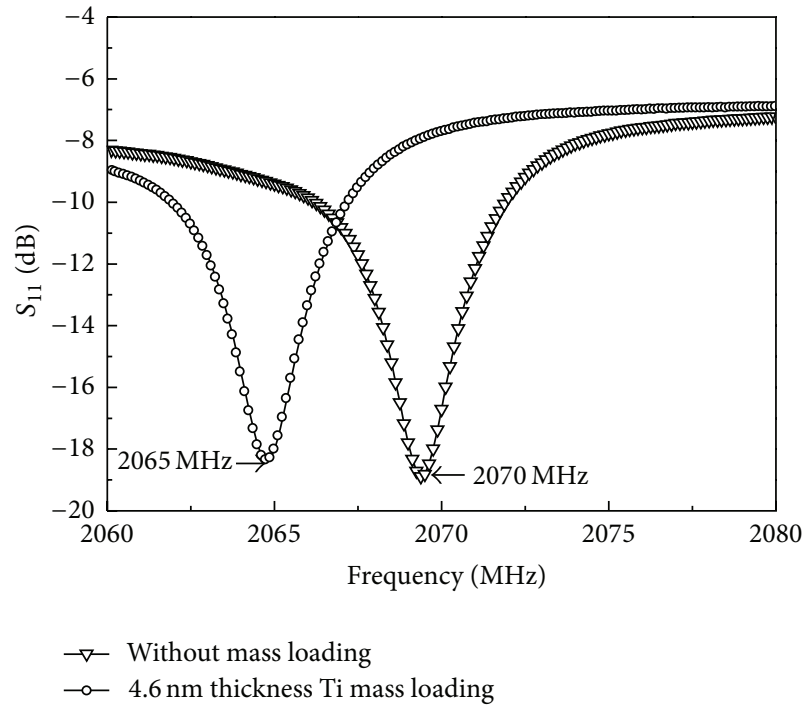

(a)

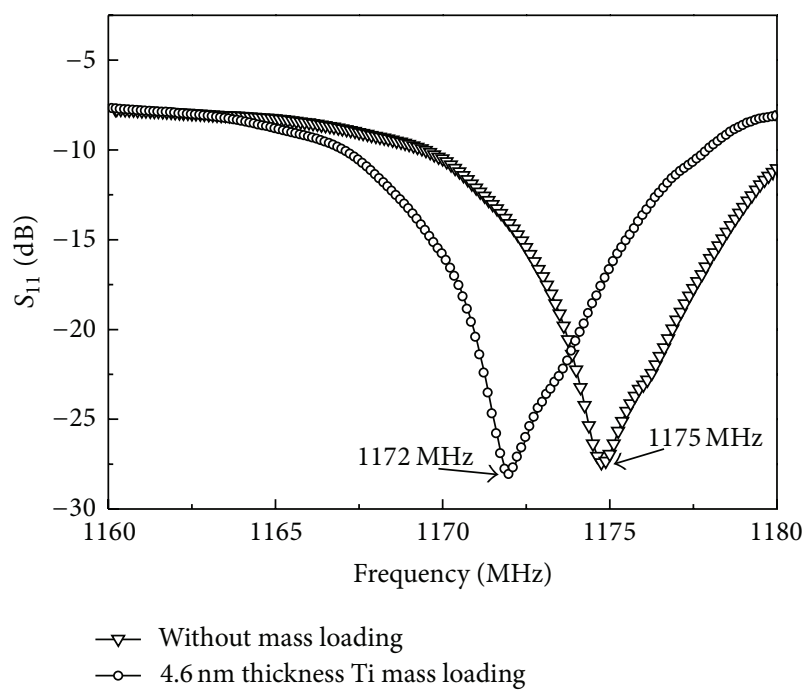

(b)

FIGURE 9: Frequency responses of the dual-mode TFBAR device under Ti mass loading. (a) Longitudinal resonant mode $\left(f_{L}\right)$ and (b) shear resonant mode $\left(f_{S}\right)$.

to evaluate the TFBAR performance. The coupling coefficient, $k_{t}^{2}$, taken from the work of Bjurström et al. and Wei et al. $[31,32]$, is expressed in terms of $f_{p}$ and $f_{S}$ as

$$
\begin{aligned}
k_{t}^{2} & =\frac{\varphi}{\tan \varphi}=\frac{[\pi / 2]\left[f_{s} / f_{p}\right]}{\tan \left[[\pi / 2]\left[f_{s} / f_{p}\right]\right]} \\
& \approx\left[\frac{\pi}{2}\right]^{2}\left[\frac{f_{p}-f_{s}}{f_{p}}\right],
\end{aligned}
$$

where $f_{S}$ is the frequency at which the magnitude of the admittance is a maximal and $f_{p}$ is the frequency at which the 


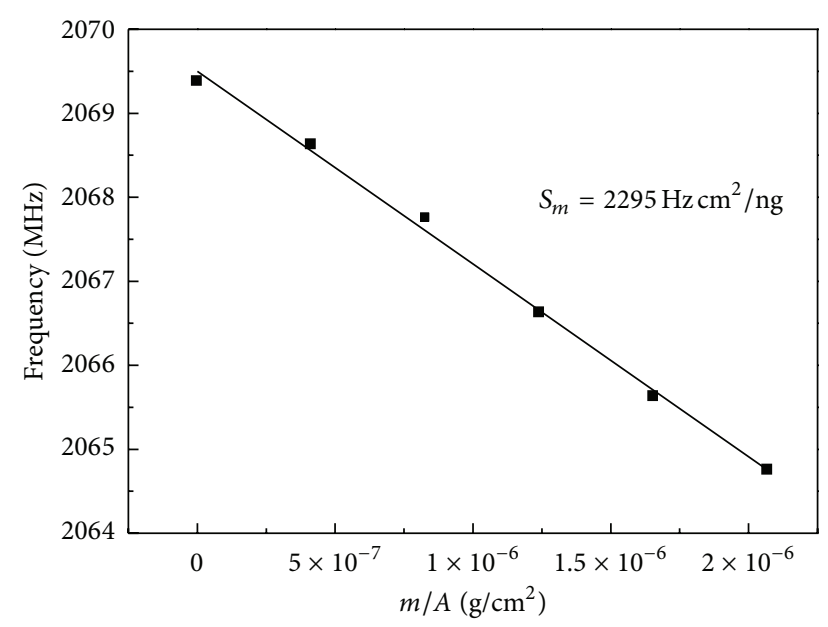

- Experiment - Linear fit of experiment

(a)

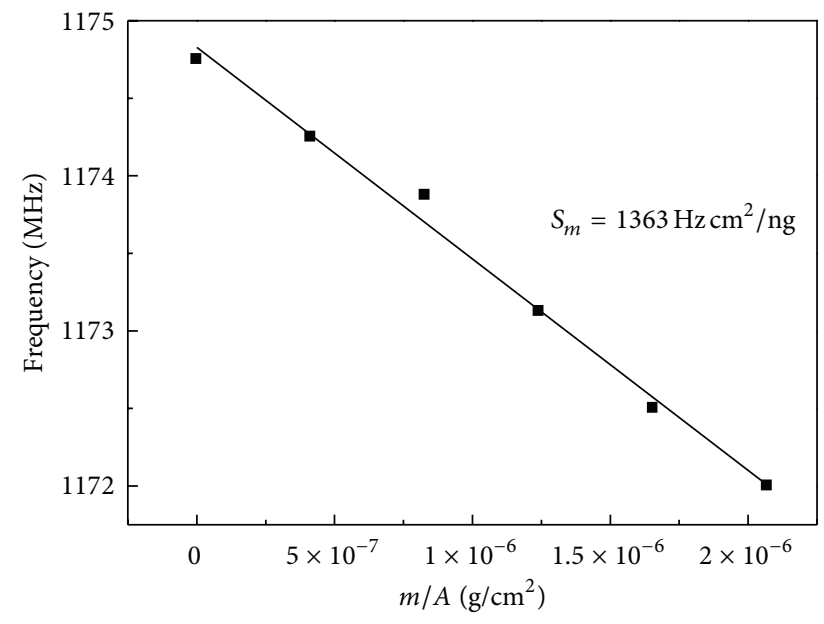

- Experiment

— Linear fit of experiment

(b)

FIGURE 10: Sensitivities of TFBAR device with various mass loading. (a) Longitudinal and (b) shear resonant mode.

magnitude of the admittance is minimal. The electromechanical coupling factors $\left(k_{L}^{2}\right.$ for the longitudinal mode and $k_{S}^{2}$ for the shear mode) in air are $0.6 \%$ and $2.1 \%$, respectively.

The mechanical quality factors $\left(Q_{L}\right.$ for the longitudinal mode and $Q_{S}$ for the shear mode) are the important parameters of dual-mode TFBAR devices in liquid environments. The mechanical quality factors $\left(Q_{L}\right.$ and $\left.Q_{S}\right)$ were defined in terms of the full width at half maximum (FWHM) of the resistance curve at resonance frequency $f_{r}$ [32] as follows:

$$
\mathrm{Q}=\left|\frac{f_{r}}{\mathrm{FWHM}}\right|_{f_{r}} .
$$

The mechanical quality factors decrease as the bandwidth increases. The FWHM of resonance frequency is defined by using the analytical software (SoftPlot 7.0, demonstration

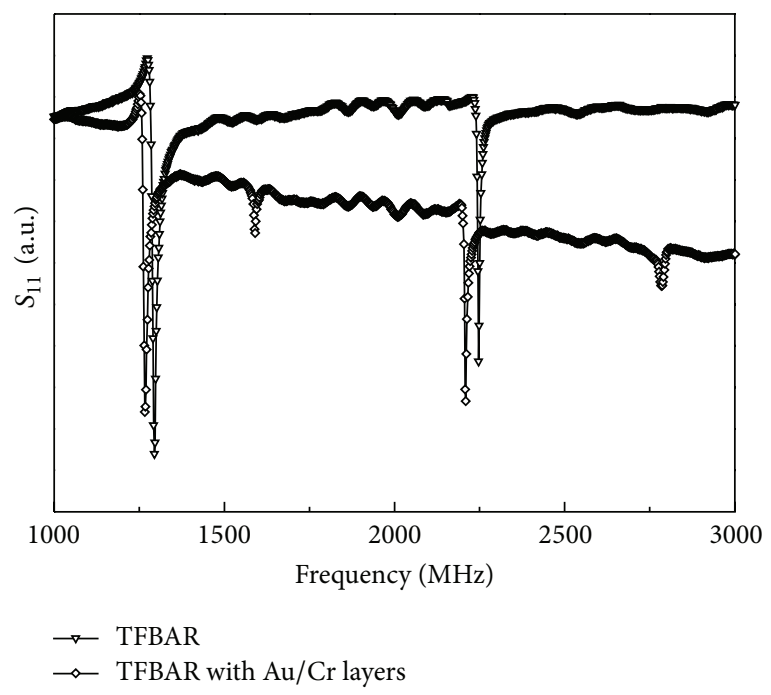

FIGURE 11: Frequency responses of dual-mode TFBAR devices with and without $\mathrm{Au} / \mathrm{Cr}$ layers.

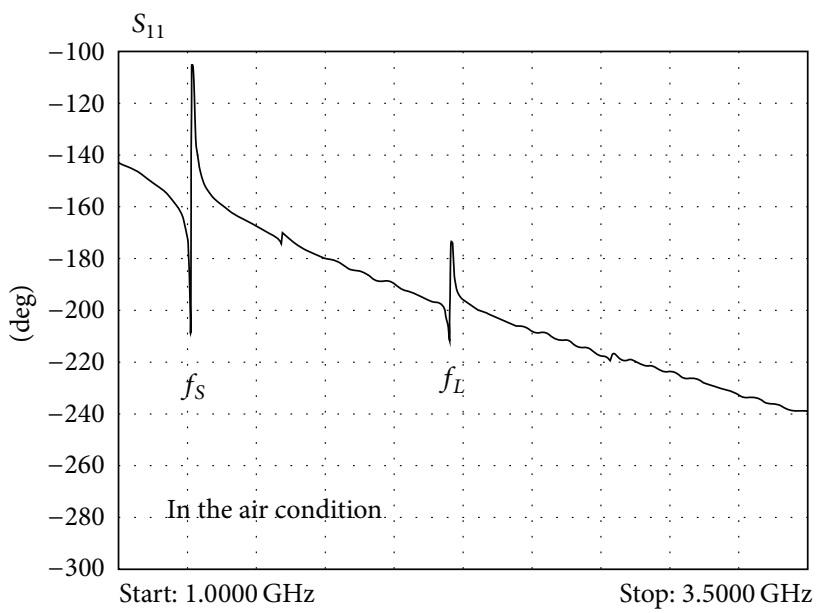

(a)

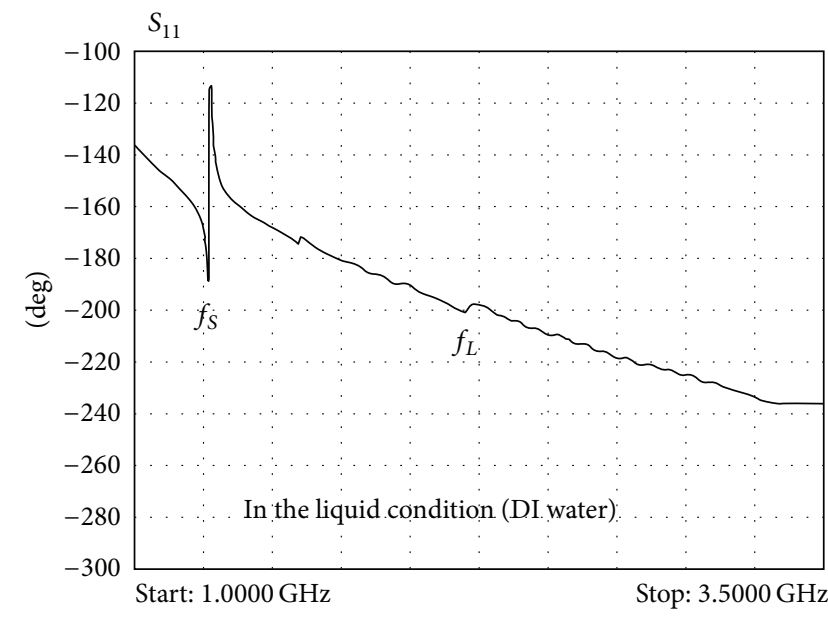

(b)

FIGURE 12: Frequency responses of TFBAR device. (a) In air environment and (b) in liquid environment. 


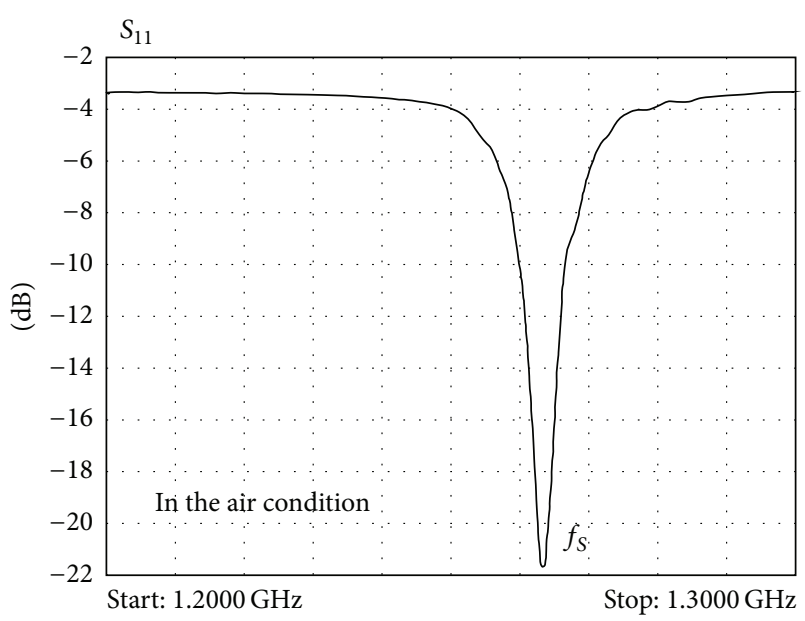

(a)

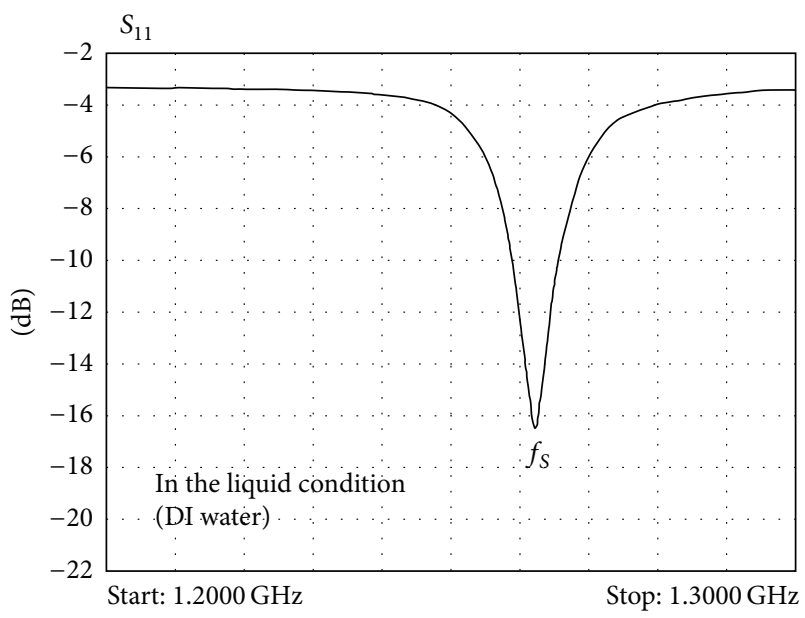

(b)

FIGURE 13: Frequency response of shear mode. (a) In air environment and (b) in liquid environment.

TABLE 3: Thin film bulk acoustic wave properties of $23^{\circ}$-tilted AlN thin films.

\begin{tabular}{lccccc}
\hline \multicolumn{3}{c}{ Mechanical quality factor } & \multicolumn{2}{c}{$\begin{array}{c}\text { Electromechanical } \\
\text { coupling coefficient (\%) }\end{array}$} \\
$\begin{array}{l}Q_{L} \\
\text { (air) }\end{array}$ & $\begin{array}{c}Q_{L} \\
\text { (liquid) }\end{array}$ & $\begin{array}{c}Q_{s} \\
\text { (air) }\end{array}$ & $\begin{array}{c}Q_{s} \\
\text { (liquid) }\end{array}$ & $k_{L}{ }^{2}$ & $k_{S}{ }^{2}$ \\
\hline 480 & 0 & 287 & 185 & $0.6 \%$ & $2.1 \%$ \\
\hline
\end{tabular}

edition). As shown in Figure 13, $Q_{S}$ is reduced from 287 to 185. However, the satisfactory response in the shear mode is maintained. Table 3 presents the thin film bulk acoustic wave properties of the $23^{\circ}$-tilted AlN layer. Additionally, a sensitivity of $15 \mathrm{~Hz} \mathrm{~cm}^{2} / \mu \mathrm{g}$, calculated from (1), is obtained in the shear mode. Therefore, the shear mode of the dual-mode FBAR device can be exploited in liquid sensing applications.

\section{Conclusion}

This paper presents a dual-mode TFBAR device that is based on c-axis-tilted AlN thin films. The frequency responses indicate that this device exhibits longitudinal and shear mode resonances. The performance of the dual-mode TFBAR under both mass loading and liquid loading is thoroughly investigated. The experimental and analytical results indicate that the longitudinal mode of TFBAR has a wide frequency variation with mass loading, indicating that the longitudinal mode is suitable for mass-sensor applications. The shear mode of TFBAR can be exploited in liquid sensor applications.

\section{Acknowledgments}

The authors gratefully acknowledge the financial support from the National Science Council, China, (nos. NSC1022221-E-237-005 and NSC 102-2221-E-366-002) and from the National Sun Yat-sen University. (The Aim for the Top University Project and NSYSU-KMU joint research project_102I003.)

\section{References}

[1] C.-L. Wei, Y.-C. Chen, J.-L. Fu, K.-S. Kao, D.-L. Cheng, and C.-C. Cheng, "UV detection based on a $\mathrm{ZnO} / \mathrm{LiNbO}_{3}$ layered surface acoustic wave oscillator circuit," Journal of Vacuum Science and Technology A, vol. 27, no. 6, pp. 1343-1346, 2009.

[2] R.-C. Lin, Y.-C. Chen, W.-T. Chang, C.-C. Cheng, and K.-S. Kao, "Highly sensitive mass sensor using film bulk acoustic resonator," Sensors and Actuators A, vol. 147, no. 2, pp. 425-429, 2008.

[3] I.-Y. Huang and M.-C. Lee, "Development of a FPW allergy biosensor for human IgE detection by MEMS and cystaminebased SAM technologies," Sensors and Actuators B, vol. 132, no. 1, pp. 340-348, 2008.

[4] R. C. Ruby, P. Bradley, Y. Oshmyansky, and A. Chien, "Thin film bulk wave acoustic resonators (FBAR) for wireless applications," in Proceedings of the IEEE Ultasonics Symposium, pp. 813-821, October 2001.

[5] J. D. Larson, R. C. Ruby, P. D. Bradley, J. Wen, S.-L. Kok, and A. Chien, "Power handling and temperature coefficient studies in FBAR duplexers for the $1900 \mathrm{MHz}$ PCS band," in Proceedings of the IEEE Ultasonics Symposium, pp. 869-874, October 2000.

[6] K. M. Lakin, K. T. McCarron, J. Belsick, and R. Rose, "Filter banks implemented with integrated thin film resonators," in Proceedings of the IEEE Ultasonics Symposium, pp. 851-854, October 2000

[7] K. M. Lakin, “Thin film resonator technology," IEEE Transactions on Ultrasonics, Ferroelectrics, and Frequency Control, vol. 52, no. 5, pp. 707-716, 2005.

[8] Q.-X. Su, P. Kirby, E. Komuro, M. Imura, Q. Zhang, and R. Whatmore, "Thin-film bulk acoustic resonators and filters using $\mathrm{ZnO}$ and lead-zirconium-titanate thin films," IEEE Transactions on Microwave Theory and Techniques, vol. 49, no. 4, pp. 769-778, 2001.

[9] R.-C. Lin, K.-S. Kao, C.-C. Cheng, and Y.-C. Chen, "Deposition and structural properties of RF magnetron-sputtered $\mathrm{ZnO}$ thin films on $\mathrm{Pt} / \mathrm{Ti} / \mathrm{SiN}_{x} / \mathrm{Si}$ substrate for FBAR device," Thin Solid Films, vol. 516, no. 16, pp. 5262-5265, 2008.

[10] R.-C. Lin, Y.-C. Chen, and K.-S. Kao, “Two-step sputtered ZnO piezoelectric films for film bulk acoustic resonators," Applied Physics A, vol. 89, no. 2, pp. 475-479, 2007. 
[11] C.-J. Chung, Y.-C. Chen, C.-C. Cheng, and K.-S. Kao, "An improvement of tilted AlN for shear and longitudinal acoustic wave," Applied Physics A, vol. 94, no. 2, pp. 307-313, 2009.

[12] C.-L. Wei, Y.-C. Chen, S.-R. Li, C.-C. Cheng, K.-S. Kao, and C.-J. Chung, "Effects of reflecting layers on resonance characteristics of a solidly mounted resonator with (1/4) $\lambda$ mode configuration," Applied Physics A, vol. 99, no. 1, pp. 271-278, 2010.

[13] European Union, Waste Electrical and Electronic Equipment [WEEE] Regulations, EU-Directive 96/EC, 2002.

[14] European Union, Restriction of the Use of Certain Hazardous Substances in Electrical and Electronic Equipment [ROHS] Regulations, EU-Directive 95/EC, 2002.

[15] H. Zhang and E. S. Kim, "Micromachined acoustic resonant mass sensor," Journal of Microelectromechanical Systems, vol. 14, no. 4, pp. 699-706, 2005.

[16] M. Minakata, N. Chubachi, and Y. Kikuchi, "Variation of caxis orientation of $\mathrm{ZnO}$ thin films deposited by DC diode sputtering," Japanese Journal of Applied Physics, vol. 12, no. 3, pp. 474-475, 1973.

[17] F. Martin, M.-E. Jan, S. Rey-Mermet et al., "Shear mode coupling and tilted grain growth of AlN thin films in BAW resonators," IEEE Transactions on Ultrasonics, Ferroelectrics, and Frequency Control, vol. 53, no. 7, pp. 1339-1343, 2006.

[18] M. Link, M. Schreiter, J. Weber et al., "C-axis inclined $\mathrm{ZnO}$ films deposited by reactive sputtering using an additional blind for shear BAW devices," in Proceedings of the IEEE Ultrasonics Symposium, vol. 1, pp. 202-205, September 2005.

[19] J. S. Wang, K. M. Lakin, and A. R. Landin, "Sputtered caxis inclined piezoelectric film and shear wave resonators," in Proceedings of the 37th IEEE Frequency Control Symposium, pp. 144-146, Philadelphia, Pa, USA, 1983.

[20] J. Weber, W. M. Albers, J. Tuppurainen et al., "Shear mode FBARs as highly sensitive liquid biosensors," Sensors and Actuators A, vol. 128, no. 1, pp. 84-88, 2006.

[21] M. Link, J. Weber, M. Schreiter, W. Wersing, O. Elmazria, and P. Alnot, "Sensing characteristics of high-frequency shear mode resonators in glycerol solutions," Sensors and Actuators B, vol. 121, no. 2, pp. 372-378, 2007.

[22] G. Wingqvist, J. Bjurström, L. Liljeholm, V. Yantchev, and I. Katardjiev, "Shear mode AlN thin film electro-acoustic resonant sensor operation in viscous media," Sensors and Actuators B, vol. 123, no. 1, pp. 466-473, 2007.

[23] G. Wingqvist, "AlN-based sputter-deposited shear mode thin film bulk acoustic resonator (FBAR) for biosensor applications-a review," Surface and Coatings Technology, vol. 205, no. 5, pp. 1279-1286, 2010.

[24] G. Wingqvist, H. Anderson, C. Lennartsson, T. Weissbach, V. Yantchev, and A. L. Spetz, "On the applicability of high frequency acoustic shear mode biosensing in view of thickness limitations set by the film resonance," Biosensors and Bioelectronics, vol. 24, no. 11, pp. 3387-3390, 2009.

[25] M. Akiyama, K. Nagao, N. Ueno, H. Tateyama, and T. Yamada, "Influence of metal electrodes on crystal orientation of aluminum nitride thin films," Vacuum, vol. 74, no. 3-4, pp. 699703, 2004.

[26] K. Biswas and S. Kal, "Etch characteristics of $\mathrm{KOH}, \mathrm{TMAH}$ and dual doped TMAH for bulk micromachining of silicon," Microelectronics Journal, vol. 37, no. 6, pp. 519-525, 2006.

[27] C. M. Horowitz, R. A. Monetti, and E. V. Albano, "Competitive growth model involving random deposition and random deposition with surface relaxation," Physical Review E, vol. 63, no. 6, Article ID 066132, 2001.
[28] I. Petrov, P. B. Barna, L. Hultman, and J. E. Greene, "Microstructural evolution during film growth," Journal of Vacuum Science and Technology A, vol. 21, pp. S117-S128, 2003.

[29] L. Qin, Q. Chen, H. Cheng, and Q.-M. Wang, "Analytical study of dual-mode thin film bulk acoustic resonators (FBARs) based on $\mathrm{ZnO}$ and AlN films with tilted c-axis orientation," IEEE Transactions on Ultrasonics, Ferroelectrics, and Frequency Control, vol. 57, no. 8, pp. 1840-1853, 2010.

[30] G. Sauerbrey, "Verwendung von schwingquarzen zur wägung dünner schichten und zur mikrowägung," Zeitschrift für Physik, vol. 155, pp. 206-222, 1959.

[31] J. Bjurström, D. Rosén, I. Katardjiev, V. M. Yanchev, and I. Petrov, "Dependence of the electromechanical coupling on the degree of orientation of c-textured thin AlN films," IEEE Transactions on Ultrasonics, Ferroelectrics, and Frequency Control, vol. 51, no. 10, pp. 1347-1353, 2004.

[32] C.-L. Wei, Y.-C. Chen, C.-C. Cheng, and K.-S. Kao, "Solidly mounted resonators consisting of a molybdenum and titanium Bragg reflector," Applied Physics A, vol. 90, no. 3, pp. 501-506, 2008. 

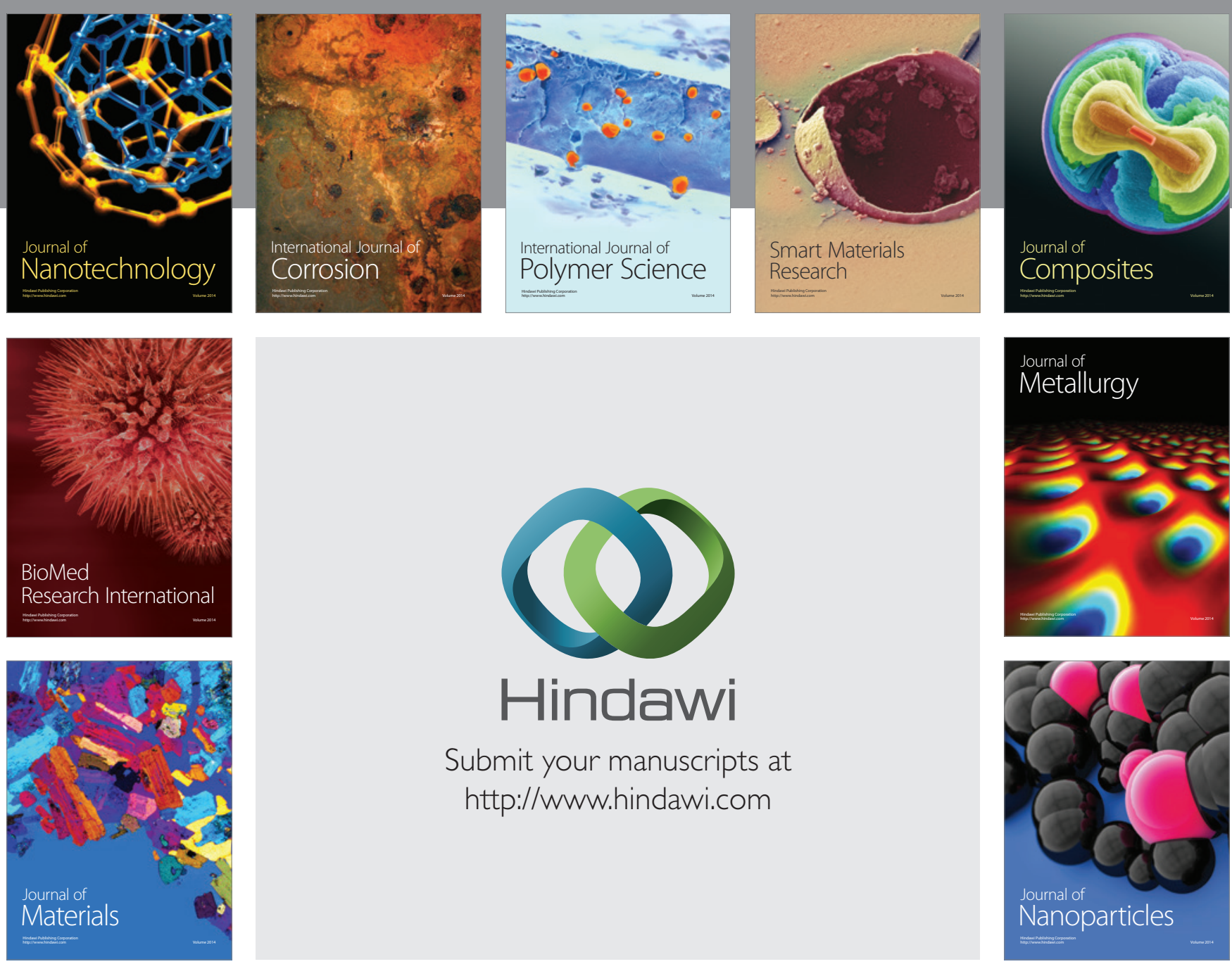

Submit your manuscripts at http://www.hindawi.com
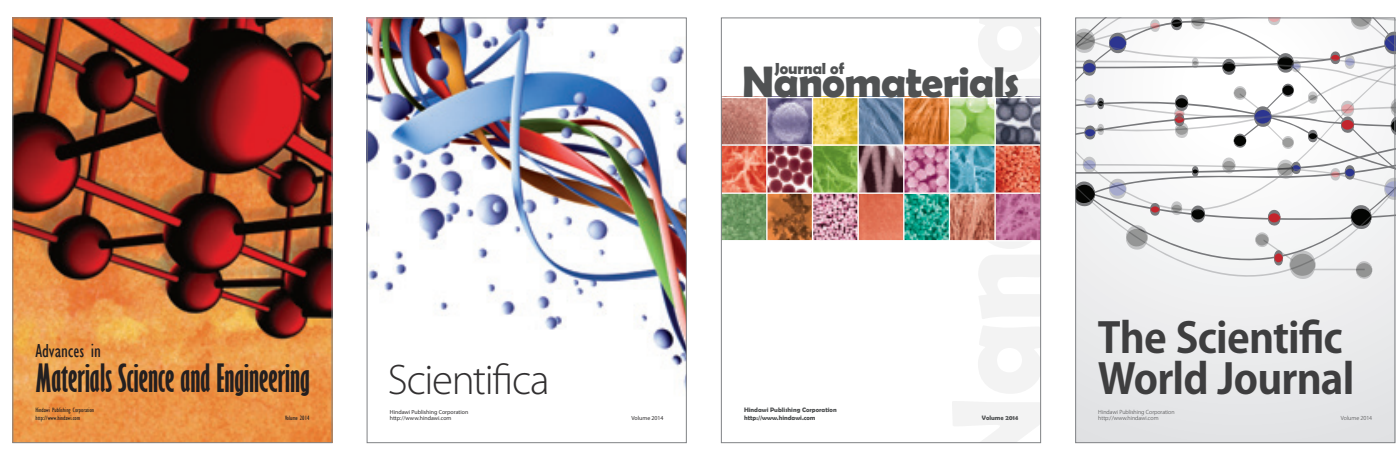

\section{The Scientific World Journal}
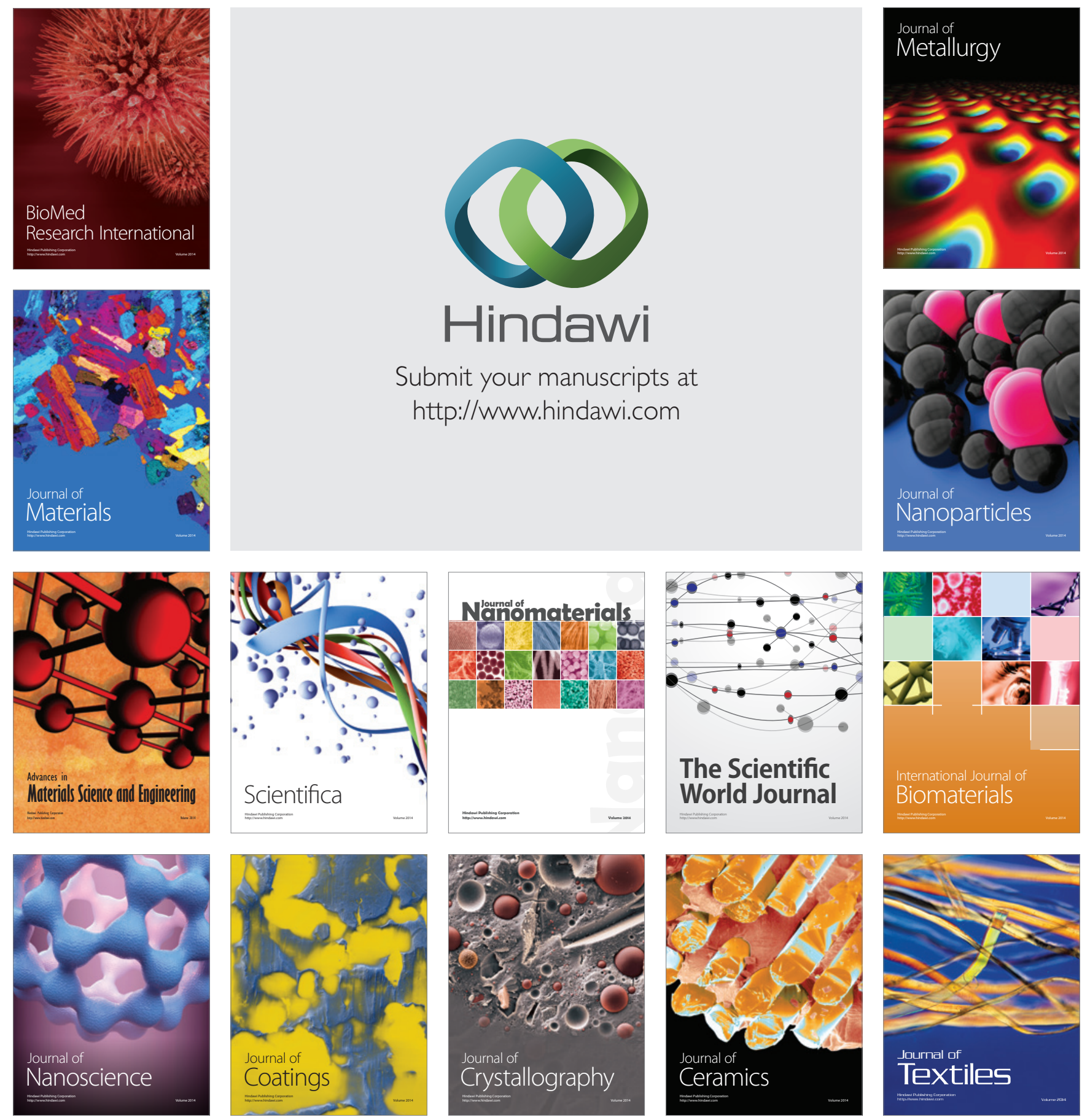